\title{
El objeto puro en Meinong
}

\author{
VÍCTOR VELARDE-MAYOL \\ Department of Philosophy \\ Seton Hall University \\ velardvi@shu.edu
}

Resumen: La pieza fundamental de la teoría del objeto de Meinong es la noción de objeto puro, que es aquel que está libre de todo ser. Gracias a esta noción, es posible justificar una teoría coherente de la predicación donde el sujeto puede estar constituido por ficciones, e incluso por objetos imposibles. Algunos filósofos analíticos, sin entender bien la teoría del objeto de Meinong, como es el caso de Russell, rechazaron la idea de objetos imposibles porque violaba el principio de no contradicción. Por el contrario, parece ser absolutamente necesario el objeto imposible para poder formular el mismo principio de no contradicción. A continuación se analizará la posición del objeto puro en relación con los diferentes estados del objeto y otros objetos del conocimiento.

Palabras clave: representación, juicio, objetivo, intencionalidad

\begin{abstract}
The notion of pure object, which is the object free of any being, is the fundamental piece of Meinong's Theory of Objects. Thanks to this notion, it is possible to justify a coherent theory of predication where the subject can be constituted by fictitious objects, even impossible objects. Some analytic philosophers, without a good understanding of Meinong's Theory of Objects, as in the case of Russell, have rejected the idea of impossible objects because it violates the principle of non-contradiction. On the contrary, the impossible object seems to be absolutely necessary in order to formulate the very principle of non-contradiction. An analysis of the position of the pure objects in relation to both the different states of an object and other objects of knowledge follows.
\end{abstract}

Key words: representation, judgment, objective, intentionality

En su teoría del objeto, Meinong desarrolla una de las tesis más importantes de su pensamiento; a saber, que todo objeto implica un objeto puro (reiner Gegenstand). Objeto puro significa lo que es sólo objeto, que no es una cosa, ni un existente, ni siquiera ideal, pero se implica en todo otro objeto existente o ideal.

Para entender la noción de objeto puro se debe analizar primero la noción de objeto; después, su relación con lo que Meinong llama "objetivo" (Objectiv), y, por último, introduciremos el principio de independencia, que es el paso esencial para comprender, finalmente, lo que Meinong llama objeto puro.

Hay importantes consecuencias de la noción meinonguiana de objeto que voy a analizar en relación con otros pensadores, especialmente con 
lo que se refiere a las nociones metafísicas de "ser" y "esencia". Al final indicaré brevemente en qué sentido hay un paralelismo entre Meinong y el filósofo medieval Duns Scoto.

\section{La idea de objeto}

El uso corriente del término "objeto" es el de cosa, pero éste no es el preciso significado que Meinong le da. ¿Qué definición puede darse de la noción de objeto? Según Meinong, no es posible dar una definición cabal de objeto: "objeto" es una noción tan primitiva que, como tal, no permite una definición en el sentido estricto. Esto es, no hay un concepto más básico y genérico al que uno pueda referirse para proporcionar una definición estricta. Veamos este punto.

Según la lógica clásica —a la que se refiere Meinong—, la definición perfecta es según el genus y la differentia; pero, como lo hace notar, no hay una definición rigurosa por medio del género próximo y la diferencia específica, ya que todo es objeto, todo cae bajo la posibilidad de ser objeto. ${ }^{1}$ Por tanto, el genus es tan objeto como la differentia. Nótese que algo parecido pasa con la noción de ente en Aristóteles: el ente no sólo no es un género, sino que no cabe de él una definición por el género y la diferencia, pues todo cae bajo la noción de ente. No obstante las semejanzas, en este punto concreto, entre Meinong y Aristóteles, la noción de ente qua ente es formalmente distinta de la de objeto qua objeto, como se notará más adelante.

Si bien no es posible ofrecer una definición rigurosa de objeto, sí es posible hacer una descripción imperfecta de los objetos mediante el recurso a las vivencias que tienden a ellos, y mediante una descripción etimológica. Empecemos por lo segundo. La etimología de la palabra "objeto" nos puede descubrir interesantes elementos. En español tenemos la palabra "objeto", que viene del latín "obiectum". En alemán hay dos palabras; a saber, "Objekt" y "Gegenstand", que históricamente se han usado más o menos indistintamente, aunque Meinong —como veremos- las distingue en su teoría del objeto. El término "Objekt" es, como la palabra española "objeto", obviamente de origen latino, mientras que el término "Gegenstand" es de raíces germanas. Sorprendentemente, ambas palabras tienen el mismo significado etimológico: ob-iectum significa lo que está arrojado o yace (iectum) en frente (ob); paralelamente, Gegen-stand significa lo que está o yace (stand) en fren-

1 "Was zunächst Gegenstand ist, formgerecht zu definiren, dazu fehlt es genus wie an differentia; denn alles ist Gegenstand" (Meinong 1978c, p. 12). 
te (Gegen). En otras palabras, objeto es lo contrapuesto, lo enfrentado o, más específicamente en nuestro caso, lo contrapuesto a un acto psíquico.

Según la descripción del objeto por la vivencia que lo tiende a él, tenemos que objeto es todo aquello a lo que se dirige un acto psíquico, y por acto psíquico se entiende todo acto de representación, de juicio, de sentimiento, etc. Esta definición descriptiva es una conclusión que Meinong deriva de un principio del todo evidente: no se puede pensar sin pensar algo, donde "algo" es el objeto. Es del todo imposible conocer sin conocer algo; el objeto es necesario para el acto de conocer, y el acto de conocer requiere el objeto, aunque uno y otro no están en la misma relación. Mejor sería decir que el objeto es el "contrapolo" del polo que es el acto. Como los objetos de los actos psíquicos que no son cognoscitivos son considerados también, Meinong sugiere la necesidad de una ciencia cuyo tema sea precisamente la totalidad de los objetos, una teoría de los objetos. ${ }^{2}$

Los antecedentes de la teoría del objeto de Meinong son fácilmente visibles en la filosofía de la intencionalidad de Brentano, del cual fue discípulo al mismo tiempo que Husserl. Para Brentano, una representación es siempre representación de algo, y esta característica "representación-de-algo" es lo que él llama intencionalidad. Así que objeto es lo que hace de término intencional de una representación. Nótese que objeto no sería entonces la cosa misma en cuanto cosa, sino la cosa en cuanto término intencional, y el ser que adquiere en la representación es lo que Brentano a veces llama "in-existencia intencional", la referencia a algo como objeto. ${ }^{3}$ De esta suerte, los objetos representados en cuanto representados, son propiamente denominados "objetos". Desde luego, la cosa representada es realmente una cosa (res), aunque en cuanto representada adquiere un ser intencional: el ser-objeto (obici) es una denominación extrínseca de la cosa, y, como denominación extrínseca, no es una cosa.

Como ya Brentano notara antes que Meinong y Husserl, es de suma importancia distinguir entre lo objetivado en cuanto tal y el acto que lo objetiva. Lo contrapuesto y el contraponer se distinguen como el algo al que el acto psíquico se dirige y el acto psíquico mismo. Pero es más interesante detectar que lo contrapuesto, el objeto, es en realidad el contraponerse. El objeto desde el punto de vista de la vivencia es "ser-

${ }^{2}$ Cfr. Meinong 1972a, pp. 483-488. Específicamente, Meinong habla de una ciencia de los objetos de pensamiento: "Eine Wissenschaft vom Gegenstande des Erkennens" (ibid., p. 485).

${ }^{3}$ Cfr. Brentano 1924, libro 2, n. 9. 
objeto-de". El contraponerse (el ser-objeto-de) no es el contraponer (el acto psíquico), como el obici no es el obicere. El acto de objetivar es lo que hace que algo pueda ser objeto, y el objeto, así considerado, es simplemente su ser-objeto-de, la pura formalidad de objeto. En el lenguaje más conocido de Brentano, se diría que el representar constituye lo representado en cuanto representado; a saber, su objeto intencional.

\section{El ámbito de la teoría del objeto}

Los objetos que se constituyen intencionalmente por los actos cognoscitivos no son únicamente los existentes. La totalidad de lo que existe, incluyendo lo que ha existido y lo que existirá, es infinitamente más pequeña si lo comparamos con la totalidad de los objetos. Incluso lo ideal sobrepasa infinitamente la extensión de lo existente, presente, pasado o futuro. Si junto a los objetos existentes hay otros no existentes, éstos deberán constituirse intencionalmente también de algún modo para justificar el poder ser tema de una predicación verdadera.

Meinong piensa que los llamados objetos inexistentes han sido obliterados en la historia de la filosofía, y que su olvido es una consecuencia negativa de lo que llama "prejuicio en favor de lo real". ${ }^{4}$ Meinong llega a esta conclusión al detectar la falta de atención que la mayoría de los filósofos han prestado a los objetos inexistentes, a pesar de que los objetos inexistentes son esenciales para entender no sólo el conocimiento humano, sino también principios lógicos tan importantes como el de no contradicción.

Para enunciar el principio de no contradicción —es imposible que algo exista y no exista en el mismo sentido- se ha de representar tanto el objeto "lo que existe" como el objeto "lo que no existe" (lo inexistente), de lo contrario no se podría enunciar el principio más fundamental de la filosofía. De esta suerte, el objeto inexistente entra en escena desde el comienzo de nuestro conocimiento de lo real y lo acompaña siempre.

Es mi sentir que Meinong va demasiado lejos al atribuir el olvido de lo inexistente a un supuesto "prejuicio en favor de lo real". Hubiera sido

\footnotetext{
${ }^{4}$ Meinong denuncia "Das Vorurteil zugunsten des Wirklichen" (el prejuicio en favor de lo real) como un prejuicio injustificado que hace imposible entender los objetos matemáticos, que son objetos inexistentes: "Zusammen mit dem oben berührten Vorurteil zugunsten der Wirklichkeitserkenntnis lässt diese prinzipielle Unabhängigkeit der Mathematik von der Existenz eine Tatsache verstehen, die ohne Berücksichtigung dieser Momente billig befremden könnte" (Meinong 1972a, p. 488). Cfr. otros lugares en Meinong 1978a, pp. 60, 128 y 134.
} 
mejor decir que hay "una inclinación natural por lo real", ya que en la noción de prejuicio implica la descalificación de injustificada, y creo que la inclinación natural por lo real está plenamente justificada por cuanto entendemos lo que no es real a semejanza de lo real. Un tratamiento de este importante tema requeriría un estudio independiente del que aquí se lleva a cabo.

Un buen ejemplo de lo que Meinong llama "prejuicio en favor de lo real" sería la noción de objeto que propone Frege. Para éste, objeto es algo concreto, un individuo existente, una cosa con existencia extramental. El criterio fregueano es puramente ontológico, a la vez que ignora el elemento gnoseológico. Por el contrario, para Meinong, el criterio es principalmente gnoseológico, a saber, el ser término (intencional) de un acto psíquico. Ahora bien, resulta que etimológica y realmente, la noción de objeto no es ontológica, sino gnoseológica: la denominación de objeto es un connotado extrínseco de la cosa real; esto es, ser-objeto (el obici) no es una afección real en la cosa, sino una denominación desde fuera, desde el cognoscente. De aquí se tiene que a la concepción cosista de objeto de Frege se opone la concepción intencional y gnoseológica de Meinong, que tiene a su favor la propia etimología de la palabra objeto, como ya se anotó antes. Meinong no niega la existencia de cosas, lo que niega es que uno pueda referirse a ellas sin que antes se las constituya en objetos: no es posible conocer algo sin que este algo sea objeto. En este sentido, Meinong no se llama a sí mismo "realista", sino "objetivista".

Tenemos, pues, que todo es objeto, ${ }^{5}$ o mejor, todo es objeto de un posible pensamiento. Por el mero hecho de que algo es pensado es eo ipso objeto. Sólo algo que no fuera objeto de un posible pensamiento sería cosa sin ser a la vez objeto. Quizá, un tesoro olvidado en el fondo del mar, que nadie conoce, sería un caso de una cosa que no es un objeto. Pero esto es en realidad un imposible, pues la tesis de que "todo es objeto de un posible pensamiento" no se limita a que en este momento nadie lo conozca, ya que también se extiende a lo conocido en el pasado o a lo que se conocerá en el futuro. Pero incluso esto es también incorrecto, ya que "ser-objeto-de-un-posible-pensamiento" sería válido incluso si es un hecho que nadie lo conoció, lo conoce, ni lo conocerá. La posibilidad de la que se habla aquí implica que sea posible conocerlo aunque ningún

${ }^{5}$ La expresión "todo es objeto" no significa "todo objeto es un objeto", que es una tautología, sino "todo lo que es (pensable), es objeto". Nótese que objeto es diferente de ser; el ser se dice objeto cuando dice una relación con una conciencia. Ser y objeto no son sinónimos, ni absolutamente idénticos, sino formalmente distintos, aunque puedan ser materialmente idénticos. 
cognoscente humano lo conozca de hecho en el presente, el pasado o el futuro. Por consiguiente, es suficiente para calificar como objeto que sea cognoscible por un posible conocimiento. Meinong sugiere incluso algo más radical, que estaría de acuerdo con la siguiente fórmula: aunque no haya nadie que lo conozca en el presente pasado o futuro, al menos es posible concebir un intelecto infinito que lo pueda conocer. ${ }^{6}$ De esta suerte, todo cae en la categoría de objeto. En este sentido, me parecen equivalentes (aunque no formalmente idénticas) las expresiones: "todo es objeto o puede ser objeto", y "todo es objeto para la inteligencia infinita", por cuanto la inteligencia infinita es acerca de lo real pasado, presente, y futuro, y de lo posible que nunca va a ser real. ${ }^{7}$

Meinong ahora concluye que si todo es objeto, entonces, una ciencia de los objetos sería la ciencia más universal, más incluso que la ciencia del ente qua ente, la metafísica. Según nuestro autor, el ente es simplemente otro objeto más, precisamente un objeto real o existente, mientras que la teoría del objeto tendría que habérselas con todos los objetos, no sólo con los existentes. La idea de que la metafísica era la ciencia más universal sería una de las consecuencias del prejuicio en favor de lo real. ${ }^{8}$

Un metafísico, como Aristóteles, rechazaría esta última conclusión, porque aunque la metafísica trata de los entes reales, también trata de los entes irreales. El concepto de ente es análogo; esto quiere decir que considera al ente real como primer analogado, y al irreal en referencia al ente real. Posteriormente, los metafísicos depuraron esta idea diciendo que la metafísica trata del ente real y del irreal ad instar entes; esto es, como si emulara un ente real.

No obstante, Meinong tiene razón al indicar que la ciencia del objeto es universal, y aunque es problemático que sea más universal que la metafísica, se ha de dar crédito a Meinong por cuanto en la metafísica clásica de Aristóteles se ha de incluir en el objeto de la metafísica los transcedentales del ente, entre los que se encuentra el transcendental

${ }^{6}$ Cuando Meinong habla de "una posible inteligencia infinita" no está aquí probando la existencia de ninguna inteligencia infinita, sino que es "posible concebir un intelecto infinito".

7 "Unter Voraussetzung einer unbegrenzt leistungsfähigen Intelligenz also gibt es nichts Unerkennbares, und was erkennbar ist, das gibt es auch, oder, weil 'es gibt' doch vorzugsweise von Seiendem, ja speziell von Existierendem gesagt zu werden pfegt, wäre es vielleicht deutlicher, zu sagen: Alles Erkennbare ist gegeben — dem Erkennen nämlich" (Meinong 1972a, § 6, p. 500).

${ }^{8}$ Meinong distingue la teoría del objeto no sólo de la metafísica sino también de la teoría del conocimiento, de la psicología, y de la lógica pura; cfr. Meinong 1972a, § 11, p. 515. 
verdadero. El ente como verdadero es el ente referido a la inteligencia, $\mathrm{y}$ en este punto se puede establecer un interesante paralelismo con la teoría del objeto.

\section{El objetivo}

Emulando a Brentano, Meinong menciona cuatro tipos de objetos ( $\mathrm{Ge}$ genstände) según los tipos fundamentales de actos intencionales. Así, hay objetos de representación, objetos de juicio, de emoción, y de deseo; a saber, objeto (Objekt), objetivo (Objektiv), dignitativo (Dignitativ) y desiderativo (Desiderativ), respectivamente. De esta cuatripartición, hay dos clases de objetos que merecen nuestra atención; a saber, el objeto (Objekt) u objeto de representación, y el objetivo (Objektiv) u objeto de juicio. ${ }^{9}$ Meinong reserva el término Gegenstand para referirse a los objetos en general, y reserva el término Objekt para referirse al caso especial de los objetos de la representación. Un objeto de representación es un número, una figura, un color, un árbol, etc. A diferencia de los objetos de representación, todos los objetivos son ideales, nunca reales, mientras que los objetos de representación (Objekte) pueden ser reales o ideales.

Hay objetos ideales que se dan junto con los existentes, como es el caso de la diferencia entre el rojo y el verde. El objeto diferencia es un objeto que se funda sobre dos objetos; a saber, el rojo y el verde. La diferencia es un objeto de orden superior, o simplemente superiora, mientras que el rojo y el verde son objetos de orden inferior, o simplemente inferiora. Lo llamativo es que mientras los objetos rojo y verde son existentes, la diferencia, que se funda en ellos, no existe propiamente, sino que tiene un ser ideal que Meinong denomina "subsistir" (bestehen). La diferencia no existe entre los objetos rojos y verdes, pero subsiste (tiene un ser ideal) entre ellos. ${ }^{10}$

El número, por ejemplo, es un objeto de orden superior que tiene como inferiora a los numerados. El número de libros de una biblioteca no está entre los libros, no es perceptible junto a los objetos reales que son los libros (los inferiora), pero el número se da junto con ellos. El ser del número, como el de la diferencia, no es, por tanto, el existir sino el subsistir (bestehen), que es el ser de los objetos ideales. ${ }^{11}$ En estos ejemplos, los objetos de orden superior, los superiora, son objetos

${ }^{9}$ Cfr. Meinong 1978c, sección B-IV, p. 20.

${ }^{10} \mathrm{Cfr}$. Meinong 1972b, Über Gegenstände höherer Ordnung und deren Verhältni $\beta$ zur inneren Wahrnehmung, pp. 377-471, especialmente, pp. 415-421.

${ }^{11}$ Meinong sólo considera el numerus numerans y no el numerus numeratus. 
que "subsisten" en los objetos de orden inferior o inferiora, que tienen existir (existieren).

No todos los objetos de orden superior se fundan en objetos existentes, aunque al final de la serie se ha de encontrar algún objeto existente. Por ejemplo, la diferencia entre dos números tiene como inferiora a dos números, y éstos a su vez son objetos de orden superior que pueden tener como inferiora objetos reales.

En estos dos ejemplos, la diferencia y el número son objetos de representación, pero esto no implica que todos los objetos de orden superior son objetos de representación, pues también el objeto (Objektiv) de juicio es siempre un objeto de orden superior. El objetivo (Objektiv), el objeto del juicio, cumple las condiciones de objeto de orden superior. ${ }^{12}$

Un objetivo es, por ejemplo, el siguiente juicio verdadero, "un caballo bermellón corre por la pradera". Gracias a este juicio, no sólo sabemos del correr de un caballo, sino también que hay un objeto peculiar (o, más precisamente, lo que Meinong llama "objetivo") por el que sé que mi juicio es verdadero. Este objeto de juicio no es ni el caballo bermellón, ni la pradera, sino el objetivo "un caballo bermellón corre por la pradera". No se juzga el objeto "caballo bermellón", sino el objetivo de que "un caballo bermellón corre por la pradera". Este objetivo es completamente distinto de los elementos que lo integran, y esto se puede ver fácilmente si se advierte que el objeto real caballo corre realmente por la pradera, e incluso el objeto real algo bermellón corre realmente por la pradera, pero "un caballo bermellón corre por la pradera" no corre a su vez por la pradera, ni hace ninguna actividad física.

El objetivo es el objeto directo del acto judicativo, y este objeto nunca existe, sino que siempre subsiste o tiene el ser como subsistir (bestehen), y esto se cumple incluso cuando los elementos que lo componen tengan existencia propia. La situación se parece a la que se encuentra en el número o la diferencia con sus inferiora, que pueden tener existencia real efectiva, mientras el objeto de orden superior sólo subsiste. El objetivo, en este sentido, es un objeto de orden superior, superius, que se funda en objetos de orden inferior o inferiora, que son el sujeto y el predicado.

Si el objetivo "un caballo bermellón corre por la pradera" fuera falso, lo sería por causa de que hay otro objetivo "un caballo bermellón no corre por la pradera" que es juzgado como verdadero, y no por causa del objeto de representación "caballo bermellón" que es parte integral del objetivo, pues el mismo objeto de representación aparece tanto en un juicio verdadero como en uno falso. Igualmente, si juzgo

${ }^{12}$ Cfr. Meinong 1978a, pp. 44-76, 131-155. 
que "no existe Pegaso", el juicio acerca de este objetivo es verdadero no por causa del objeto (de representación) Pegaso, que no existe, sino por causa del objetivo "Pegaso no existe", que a su vez no existe, sino que subsiste. ${ }^{13}$ Lo mismo se podría decir del objetivo "existen caballos bermellones", que afirma la existencia de estos caballos; pero el objetivo mismo no existe, sino que subsiste. Si el objetivo "existen caballos bermellones" existiera simplemente porque existen sus partes integrantes (aquí, los caballos bermellones), entonces, por el mismo razonamiento, el objetivo que incluyera al primer objetivo - "'existen caballos bermellones' existe" - existiría también, y así ad infinitum, creando una interminable cadena de existencias reales y efectivas por el mero hecho de juzgar la existencia de algo. Para evitar este indeseable regreso al infinito, Meinong sostiene que un objetivo no puede existir, sino que tiene un ser ideal, el subsistir (bestehen). ${ }^{14}$

4. El principio de independencia de la esencia respecto del ser: el fundamento del objeto puro

En las antípodas de la teoría del objeto de Meinong, se encuentra el reísmo del último Brentano, que mantiene una noción cosista del objeto, por cuanto identifica objeto con cosa. Brentano ideó una teoría -la teoría de las ficciones- por la que uno se podía deshacer fácilmente de los entes ficticios, y en general de todo objeto ideal. Según este periodo de la filosofía de Brentano, los objetos ideales, que aparecen en proposiciones abstractas, son sólo legítimos si las proposiciones en que aparecen pueden ser traducidas a otras en donde los términos designan cosas concretas individuales. De esta suerte, todo objeto tiene que ser reducido a una cosa concreta individual. ${ }^{15}$

Si aplicamos el reísmo de Brentano a lo que Meinong sostiene, tendremos que el objetivo " 'Pegaso no existe' subsiste" simplemente niega o rechaza que Pegaso sea una cosa individual concreta, y el objetivo “'Hay caballos bermellones' subsiste” simplemente afirma que los caballos bermellones son cosas individuales concretas. Según Brentano, no hay necesidad de postular un ser —el subsistir (bestehen) - para las proposiciones (los objetivos meinonguianos) y otros objetos ideales. No obstante el esfuerzo de Brentano por eliminar el ser ideal, es impo-

${ }^{13}$ Cfr. Meinong 1978a, pp. 12, 15, 30 s.; y Meinong 1972b, pp. 386-388.

${ }^{14}$ Cfr. Meinong 1978a, pp. 64, 69, 74, 80, 216; y Meinong 1978b, pp. 39, 130, 153, 159, 160, 197, 715.

${ }^{15}$ Cfr. Kotarbinski 1976, pp. 194-203. 
sible aplicar su teoría a la tesis meinonguiana de la independencia de la esencia respecto del ser, que se expondrá a continuación.

Podemos hacer juicios verdaderos acerca de objetos que existen, de objetos que no existen, y, lo que puede parecer más paradójico, de objetos que son intrínsicamente contradictorios. Respecto de lo último, se puede formar un juicio verdadero acerca de un contradictorio al decir que lo contradictorio no existe. Por ejemplo, se pueden formular juicios verdaderos del cuadrado redondo, que no existe, ni siquiera puede existir. Se puede decir que nosotros ahora estamos pensando en el cuadrado redondo, que es un imposible. Lo imposible no es el acto de juzgarlo, sino el objeto "cuadrado redondo", ya que el acto psíquico es real, y nada real puede ser imposible. Y como todo acto intencional tiene su objeto, entonces, el acto de pensar en un cuadrado redondo tendrá al círculo cuadrado como su objeto.

Uno puede decir que "el cuadrado redondo es imposible" y esto es una verdad necesaria, o también se puede decir que "el cuadrado redondo no puede existir", que también es una verdad necesaria, e incluso se pueden hacer juicios del tipo "el cuadrado redondo es redondo", que es una verdad analítica por cuanto el predicado está incluido en el sujeto. El simple hecho de que uno distingue un objeto imposible de otro (por ejemplo, el cuadrado redondo del hierro de madera), o que se puedan decir verdades necesarias y analíticas de objetos imposibles, es suficiente para afirmar que lo que hace de sujeto - el objeto imposible- debe ser antes representado de alguna manera.

Una dificultad muy común para aceptar la doctrina meinonguiana de los objetos imposibles es el error empirista que sostiene que para pensar algo real se debe ejercer un acto de pensamiento igualmente real -algo que es cierto-; de igual manera, para pensar algo imposible se debería ejercer un acto imposible de pensamiento, lo cual es imposible. Este error no tiene en cuenta la doctrina de la intencionalidad, que distingue netamente entre el acto psíquico y su objeto intencional. Esto es, para pensar un imposible no se necesita un acto imposible de pensamiento, de igual manera que para pensar la nada no se requiere una nada de pensamiento, y para pensar un color rojo no se requiere del pensamiento ningún tinte encarnado.

Meinong da un paso más radical. Hay verdades que se mantienen incluso de aquello que nunca fue ni es objeto de pensamiento (pero puede ser pensado). Tales objetos tienen al menos la característica de "no ser pensados por nadie". De esta suerte, aunque nadie hubiere pensado en el cuadrado redondo, el objetivo "el cuadrado redondo no existe" sería aún necesariamente verdadero. Para ser objeto no se necesita que 
exista ni siquiera que subsista. De aquí la aparentemente paradoja de la fórmula meinonguiana: "hay objetos de los que es verdad decir que no hay tales objetos", ${ }^{16}$ esto es, hay objetos que no existen.

Meinong afirma que se puede decir que hay objetos que tienen existencia, otros que tienen subsistencia, y finalmente otros objetos que no tienen ni existencia ni subsistencia, no tienen ser alguno, como es el caso de los objetos imposibles, que ni existen ni subsisten. La independencia del ser del objeto respecto de su naturaleza es tal que, para saber si un objeto existe o no, antes se lo ha tenido que pensar sin que su ser se incluya. Incluso para saber acerca de un objeto, su ser no entra en la consideración de ese objeto. Uno puede analizar la naturaleza de una roca, un ave, o un planeta sin que sea necesario indicar su ser. De aquí, Meinong establece la importante tesis de la independencia de la esencia (Sosein) respecto del ser (Sein) de un objeto.

Este principio establece que la esencia de un objeto no está afectada ni por la existencia ni por la no existencia, su no ser (Nichtsein). Su ser (y su no ser) es completamente extrínseco a su esencia. Por ello, el hecho de que no haya un cuadrado redondo no tiene relación con el hecho de que el cuadrado redondo tenga las propiedades esenciales de ser redondo y cuadrado. En este sentido, se puede decir respecto de cualquier objeto (Objekt) (precisivamente considerado) que su esencia no existe, o más correctamente, debe decirse que tanto la existencia como la no existencia es extrínseca a la índole del objeto. La esencia (Sosein) del objeto precisivamente considerada es lo que Meinong llama "objeto puro", cuyo status es el estar allende el ser (ausserseind); esto es, que el objeto puro permanece más allá del ser y del no ser. ${ }^{17}$

Esta noción de objeto ha sido rechazada por numerosos filósofos, especialmente dentro de la llamada corriente analítica. A decir verdad, no se la ha rechazado, sino que se la ha malinterpretado y se ha rechazado esa noción de objeto malinterpretada que Meinong nunca sostuvo. Uno de esos filósofos, otrora seguidor y admirador de Meinong, fue Bertrand Russell, ${ }^{18}$ que presentó su alternativa a la tesis meinonguiana en su trabajo On Denoting (que tiene algunos parecidos con el reísmo brentaniano). Aquí sólo se quiere dejar indicado que una noción tan cosista — como la de Russell— implicaría unos problemas indeseables en

\footnotetext{
16 "Es gibt Gegenstände, von denen kilt, dass es dergleichen Gegenstände nicht gibt" (Meinong 1972a, p. 490).

${ }^{17}$ Cfr. Meinong 1972a, p. 494.

${ }^{18}$ Cuando Russell escribió The Principles of Mathematics, aún admitía con Meinong un ser para los objetos no existentes. Cfr. Russell 1938, p. 449.
} 
la teoría de la predicación. ${ }^{19}$ Russell afirma que objeto y cosa son idénticos e intercambiables sin justificación previa; esto es, lo toma como punto de partida para su teoría alternativa por la que la totalidad de lo que existe tiene la misma extensión que la totalidad de lo que es objeto, y proposiciones del tipo "Hamlet no existe" o "el cuadrado redondo es imposible", que son ambas verdaderas, no tendrían sentido alguno. Pero esta identificación acrítica entre objeto y cosa afectaría también al mismo principio de no contradicción (que tanto defiende Russell), pues al afirmar que "es imposible que algo sea y no sea en el mismo sentido", se estaría pensando en algo (un objeto) que es un contradictorio (pues es y no es al mismo tiempo y en el mismo sentido), para luego predicarle que es imposible que se dé realmente; o como Meinong podría decir, que un objeto que es y no es en el mismo sentido es imposible que exista, pero esto no quita para que puede ser un simple "contra-puesto", un auténtico objeto (imposible) del acto de pensamiento: el ser-objeto, el obici, el contra-ponerse no es de suyo ningún ser, y en este punto Meinong parece tener razón. ${ }^{20}$

Russell cree que para formar proposiciones del tipo "el cuadrado redondo es cuadrado" no se necesita representarse al objeto inexistente "el cuadrado redondo" como sujeto de una proposición. Veámoslo sólo como otro medio para clarificar el pensamiento de Meinong. Russell sostiene que hay que distinguir entre la estructura sujeto-predicado, que es gramatical y superficial, y la estructura lógica que subyace a la gramatical, en la que no se necesita la noción de sujeto, sino sólo la del predicado. De esta suerte, creer que la proposición "el cuadrado redondo es cuadrado" implica pensar en el sujeto "cuadrado redondo" sería dejarse llevar por la forma gramatical, superficial y engañosa, haciéndonos creer que hay un sujeto real, objeto de pensamiento. Para Russell, la proposición "el cuadrado redondo es redondo" se compone de tres

\footnotetext{
${ }^{19}$ Para más detalle sobre los problemas de la predicación de la propuesta russelliana asumida por Quine, véase Velarde-Mayol 1998, p. 325.

${ }^{20}$ Russell objetaría que el concepto formado por el estado de cosas que consiste en que hay una $x$ tal que $x$ es cuadrado y esa misma $x$ no es cuadrada es una proposición falsa de existencia, y por tanto un pseudoconcepto, un sinsentido, o mejor, un mero flatus vocis. Pero esto es incorrecto, Russell no parece distinguir entre un sinsentido - un círculo cuadrado- y un mero flatus vocis - como por ejemplo, "ru se la ver"-, que son meros sonidos sin inteligibilidad alguna, mientras que el sinsentido "cuadrado redondo" es entendido, probablemente por todos, y distinguido de otros sinsentidos. Quien entienda el sinsentido "cuadrado redondo" sabe que no es un "hierro de madera". Otra crítica interesante al fuerte cosismo de Russell y su teoría de las descripciones puede verse en Richard Routley (1980, pp. 137-164).
}

Diánoia, vol. LII, no. 58 (mayo 2007). 
proposiciones, o mejor, es la síntesis de tres condiciones: (1) existencial: existe al menos un individuo que es cuadrado redondo, (2) unicidad: hay solamente un individuo que es cuadrado redondo, (3) condicional: si algo es cuadrado redondo, entonces es cuadrado. No puedo detenerme en lo altamente problemático de la primera y segunda condición, que implican una ontología acrítica, ${ }^{21}$ pero puedo indicar la opinión de Meinong respecto de la tercera condición, que parece más aceptable en muchos círculos de lógica simbólica.

Según la última condición, que expresaría la forma profunda de la estructura meramente gramatical de sujeto-predicado, proposiciones universales del tipo señalado se han de convertir en condicionales. Meinong objeta a la hipótesis russelliana que la reducción a condicionales de proposiciones universales cambia sustancialmente el significado de las proposiciones. En otras palabras, para ilustrar lo que Meinong tiene en mente, la descripción de la proposición sujeto-predicado ante la conciencia es vivida, desde un punto de vista fenomenológico, de un modo completamente diferente de un condicional. Esto se puede complementar con la objeción de que las proposiciones de estructura sujeto-predicado son proposiciones porque son susceptibles de tener valor de verdad (son verdaderas o falsas), mientras que las condicionales no son estrictamente proposiciones por no tener valor de verdad o falsedad.

\section{El ser del objetivo y la superación del logicismo con el objeto puro}

El principio de independencia se aplica sólo a objetos de representación y no propiamente a objetos de juicio u objetivos. Mientras el objeto $(\mathrm{Ob}$ jekt) de representación puede existir o no existir, puede subsistir o no subsistir, o puede "tener" únicamente aussersein (el estado de allende el ser); el objetivo, por el contrario, siempre tiene ser. Aunque el objeto de representación no tenga ser alguno, y por tanto sea simplemente un objeto puro, siempre se dará el caso de que ambos objetivos " $A$ existe" $\mathrm{y}$ " $A$ no existe" tengan siempre un ser propio, el subsistir. Todo objetivo subsiste, y, por tanto, es incapaz tanto de existencia, como del mero estado de aussersein.

Lo que Meinong llama el subsistir de un objetivo es su ser veritativo, su ser verdadero o falso. Si se dice que "Pegaso no existe", este objetivo subsiste como "ser" verdadero, y si se dice equivocadamente que "Pe-

${ }^{21}$ Para una interesante crítica sobre la noción de existencia en Russell en relación con Meinong, cfr. Lambert 1983, pp. 33 ss., 46 ss., y 56 ss. 
gaso existe", este objetivo también subsiste como "ser" falso. Esto es, el "ser" veritativo o subsistencia del objetivo es algo que le pertenece de suyo y es inamisible.

Meinong desarrolla en su obra Über Annhamen [Sobre la asunción] la teoría de que es posible formar objetivos en los que todavía no se ha decidido si son verdaderos o falsos. Por ejemplo, "el autor de 'El Lazarillo de Tormes' vivió en Castilla". Dado que el autor es anónimo y que poco sabemos de él, el juicio sobre su verdad o falsedad queda en suspenso pero no anulado. Meinong dice que tales objetivos son simplemente asumidos, cuyo ser es también subsistir, esto es, tienen un ser veritativo, ya que o es falso o es verdadero, aunque no lo sepamos, o lo que es lo mismo, tiene un "ser" veritable, que puede (o tiene la posibilidad de) ser afirmado o negado. La suspensión del juicio no quita que haya un juicio posible que sea de suyo verdadero o falso. El acto de juzgar como el de asumir un objetivo es un acto mental, mientras que el subsistir o ser veritativo del objetivo es un elemento a parte objecti. Uno debe cuidar la distinción entre lo que pertenece al objeto intencionado, por un lado, y al acto intencional, por el otro.

Volviendo a nuestro asunto del ser del objetivo, que hemos identificado como el ser veritativo, o el ser que resulta del hecho de que un objetivo sea verdadero o falso, entraña ciertos peligros de los que el mismo Meinong advierte: es lo que podemos llamar "logicismo". Lo que se quiere indicar con este término es la atribución de un ser al objeto que hace de sujeto de un objetivo por el mero hecho de ser parte integrante de un objetivo verdadero. Veámoslo en la forma en que Meinong lo denuncia.

El objetivo "el cinco es un número primo", no sólo es verdadero, sino también necesario. El ser verdadero del objetivo es el ser o subsistir (bestehen) de un todo donde las partes son los objetos de representación "cinco" y "número primo". Si el todo tiene ser o subsistir, entonces parece que debe esperarse que la parte "cinco" debe tener ser o subsistir también. De esta suerte, tanto este objetivo como el sujeto "cinco" subsisten. El argumento logicista traslada el ser del objetivo al ser de sus partes. El argumento se basa en la idea de que si el todo tiene ser, necesariamente las partes que lo integran han de tener ser. Meinong sostiene que el número cinco ciertamente subsiste, pero no porque recibe la subsistencia en un objetivo.

El argumento logicista parece dejarse llevar por la analogía todoparte, donde el ser del todo es el ser de la parte. De esta suerte, dado que el objetivo tiene siempre un ser —su ser veritativo-, las partes que lo componen tendrán siempre al menos el ser como subsistencia si es 
que no existen. El objetivo "el tres es mayor que el dos" subsiste, y las partes que lo componen - los objetos tres y dos- también subsisten. Por otro lado, el objetivo "el rojo es diferente del verde" también subsiste, pero las partes - los objetos rojo y verde- no sólo subsisten, sino que existen. De aquí que el logicista concluya que los objetos constituyentes de un objetivo (que es el todo) siempre tengan ser, ya sea subsistencia o existencia. En este ejemplo, los objetos "tres" y "dos" subsisten, pero no porque pertenecen a un objetivo, como la falacia logicista presupone.

Meinong rechaza este tipo de argumentación basada en la analogía todo-parte a la que considera inadecuada para analizar el objetivo. La razón se basa en el hallazgo de los objetos imposibles que no pueden tener ningún tipo de ser, ni existencia ni subsistencia. El objetivo "el cuadrado redondo es redondo" no sólo es verdad, sino apodíctico. Este objetivo subsiste (bestand) o tiene ser veritativo. Si utilizamos el argumento de la analogía todo-parte, entonces, el objeto que hace de sujeto en este objetivo deberá tener un ser. Pero nada imposible puede tener ser, la imposibilidad es la exclusión total de ser; de lo contrario, la imposibilidad no sería imposibilidad, sino posibilidad, que es precisamente lo que se rechaza. Y porque el objeto imposible no puede tener ningún tipo de ser, y su estado es sólo el de allende el ser (aussersein), entonces, no se puede aplicar la analogía del todo-parte a los objetivos.

El argumento que Meinong utiliza para justificar esto es el siguiente. Si todo objeto constituyente de un objetivo tiene que tener un ser, entonces el objetivo " $A$ no es", que subsiste, niega el ser (existencia o subsistencia) al objeto $A$. Pero si el todo exige un ser de las partes, entonces, en el objetivo " $A$ no es" se debería atribuir un ser al objeto $A$, un ser diferente de la existencia o subsistencia, quizá un tercer tipo de ser. Este tercer tipo de ser, entonces, correspondería a todo objeto qua objeto, ya que todo objeto tendría este ser, incluso cuando se le negara el ser. Este tercer tipo de ser, sería tan peculiar que no se le opondría ningún no ser de la misma clase, ya que de no ser esto así se caería en un indeseable regreso ad infinitum.

Este hipotético - y problemático- tercer tipo de ser, que no es ni existir ni subsistir, y que no tiene ninguna oposición al no ser como lo tiene el existir y el subsistir, es simple y llanamente insostenible si no se abandona la noción de ser completamente. Por ello, Meinong concluye que el estado de un objeto donde ni el ser ni el no ser se oponen es un estado de indiferencia al ser y al no ser, o un estado que está más allá del ser y del no ser, y que Meinong prefiere llamarlo "aussersein", 
"el estar más allá del ser", que es un estado del objeto que ni incluye ni excluye el ser ni su opuesto el no ser.

Propiamente, toda oposición entre ser y no ser es asunto exclusivo del objetivo y no del objeto de representación (Objekt) que pueda formar parte del objetivo. Y teniendo en cuenta que el ser del objetivo no está de ningún modo referido en general al ser del objeto constituyente (ya que la analogía todo-parte no funciona con la relación objetivoobjeto constituyente), resulta, entonces, que los objetos en cuanto tales - los objetos puros- no están esencialmente implicados ni con el ser ni con el no ser. El objetivo es acerca del ser o no ser, mientras que el objeto de representación (Objekt) lo es sólo y propiamente acerca de la esencia del objeto. De esta suerte, la captación de un objeto existente implica siempre una representación del objeto existente en el que se presenta su esencia, y un objetivo, por el que se predica su existencia.

Las anteriores reflexiones no quieren decir que el objeto no sea ni sea alguna vez, o que el ser y el no ser sean contingentes para la esencia del objeto, ya que hay objetos que existen, otros subsisten, y otros, los objetos imposibles, que necesariamente no existen. Esto es, hay objetos que llevan la garantía de no existir, o de subsistir, únicamente analizando sus esencias. Pero la cuestión de que un objeto (Objekt) exista, subsista, o no pueda existir, no es asunto del objeto (Objekt) sino del objetivo, donde se atribuye el ser o el no ser. El objeto en cuanto objeto está allende el ser; su estado es aussersein, extra-ser, fuera del ser. El objeto es, por su propia índole, exterior al ser, aunque uno de los dos objetivos -el que atribuye el ser o el no ser- sea necesario. ${ }^{22}$

\section{La pseudoexistencia y el objeto puro}

Lo que Meinong llama “objeto puro" es, sin más, el objeto (Objekt) en cuanto que objeto, el objeto de suyo, o el objeto precisivamente considerado; esto es, la esencia del objeto tal y como es captado por la representación. En este sentido, el objeto puro "tiene" aussersein, que es el estado de allende el ser, o mejor, el estado puro más allá del ser y del no ser. De aquí la importante tesis meinonguiana: todo objeto de representación, por el mero hecho de ser objeto, tiene, al menos, aussersein. El problema que ahora surge es ¿cómo es posible que un objeto existente tenga aussersein? Pues parece claro — según el principio de no contradicción- que, o bien existe, o bien no existe, pero no cabe que

\footnotetext{
${ }^{22}$ Cfr. Meinong 1978a, pp. 79 s., 242 s., 277; Meinong 1972a, pp. 490, 494; Meinong 1972c, pp. 301, 306-308, 353 s., 356, 387, 390.
}

Diánoia, vol. LII, no. 58 (mayo 2007). 
estén más allá del existir y no existir, como requiere el estado puro de aussersein. Además, el principio de no contradicción implica la ley del tercero excluido, que es lo que la doctrina del aussersein parece negar. Por consiguiente, es un imperativo, ahora, analizar cómo sea posible que el estado de allende el ser, o aussersein, es compatible con el hecho de representarnos cualesquiera objetos, sean existentes o con otro tipo de ser, e incluso sean inexistentes.

En la doctrina del objeto puro y su estado de allende el ser (aussersein), lo que Meinong quiere decir es que la esencia del objeto no es ningún tipo de ser, ya sea extramental o mental, ni siquiera el no ser, pues la atribución del ser y el no ser es extraesencial, no es una nota de la esencia. Por lo que se ha venido analizando en el principio de independencia, creo que Meinong deja claro que la esencia (Sosein) del objeto está de suyo más allá del ser y del no ser. De aquí que, dada la distinción de ser (Sein) y esencia (Sosein), la esencia no es el ser ni su falta de ser, sino que es susceptible de él; incluso más, toda esencia o tiene o no tiene ser, pero la esencia de suyo es extrínseca al ser.

La esencia (Sosein) no sólo es exterior al ser como existencia y subsistencia, sino también al ser intencional. Por ejemplo, en el objetivo "Pegaso no existe", el objeto (Objekt) Pegaso es ciertamente inexistente, y en la descripción de la esencia de este objeto no se incluye tampoco ninguna referencia a un acto de representación. Cuando se define la esencia de este objeto (Objekt) "Pegaso" no se incluye de ninguna manera el "ser intencional" (su ser-representado), que Meinong prefiere llamar "pseudoexistencia" (para evitar el término "existencia intencional" que se presta fácilmente a errores ontológicos). Esto se fundamenta en el hecho de que, para juzgar que un objeto no existe, antes se lo ha de representar, y la representación de ese objeto no puede incluir el ser, ya que la atribución del ser o el no ser es un asunto exclusivo del objetivo y no del objeto (Objekt) de representación. "Si respecto de un objeto debo juzgar que no existe - escribe Meinong-, parece que en cierto modo tengo ante todo que captarlo, a fin de predicar de él, o, dicho más precisamente, de atribuirle o de negarle el no ser." ${ }^{23}$ En otras palabras, lo único que hace la representación es captar la esencia del objeto, pero no su ser. El ser es atribuido únicamente en el objetivo. Sin el objetivo no se podría saber si un objeto (Objekt) tiene ser o no, pues es en el objetivo donde se juzga que algo tiene ser o no. En este sentido, la pseudoexistencia no está en una posición diferente, que siendo un tipo de ser, deberá pertenecer al objetivo el atribuirlo a un objeto.

${ }^{23}$ Meinong 1972a, pp. 490 y 494. 
Meinong dice explícitamente que "para no existir, el objeto necesita aún menos, si es posible, de ser representado, que para existir, y que incluso en la medida en que estuviera destinado a ello, del hecho de que llegara a ser representado, sólo podría resultar, cuando más, 'la existencia en la representación' y, por ende, para decirlo más drásticamente, 'la pseudoexistencia'". ${ }^{24}$

De aquí se tiene que la esencia de un objeto, el objeto puro, no implica ni la existencia, ni la subsistencia, ni siquiera su ser-representado, el ser intencional o pseudoexistencia. Esto no quita que todo objeto, para ser objeto, tiene que ser representado, pero esta atribución sólo es lograda cuando forma parte de un objetivo.

Lo más interesante de esta posición es que se ha llegado a una noción de objeto, que aunque inicialmente se lo definió como el término de un acto intencional, no incluye en él ningún tipo de ser, tampoco su ser-objeto-de-representación, o lo que es lo mismo, el objeto puro no implica ningún "contrapolo" explícito. El objeto puro está más allá del ser y del no ser, más allá del existir y del pseudoexistir, más allá del ser extramental y del ser mental.

Unas observaciones aclaratorias pueden ayudar a entender el pensamiento de Meinong. Por un lado, se dice que algo es "objeto" porque es el "contrapolo" intencional del polo que es el acto intencional. De esta suerte, parece que en la definición del objeto debe ponerse su relación con el acto intencional. No obstante, aunque esto es cierto, y lo admite Meinong, es incompleto. Es necesario distinguir entre dos aspectos del objeto que nuestro filósofo utiliza, pero no me parece suficientemente claro. En todo objeto se han de distinguir dos elementos: por un lado, lo que hace de objeto, y por otro, lo que formalmente hace que algo sea un objeto. Lo que hace de objeto es el contenido del objeto, mientras que lo que hace a algo (el contenido) ser formalmente un objeto es el ser término de una intención. Si utilizamos, cum grano salis, una analogía con la teoría hilemórfica aristotélica, el contenido sería la materia del objeto, y el ser término sería la forma del objeto. El contenido de un objeto no sería objeto si no fuera término de un acto intencional, pero el ser término de un acto intencional sería vacío si no tuviera un contenido. Veamos cómo estas observaciones sirven para entender el pensamiento de nuestro autor.

Meinong comienza con la descripción del objeto desde un punto de vista formal (la forma de ser objeto), como aquello a lo que se dirige un acto intencional. Pero luego pasa a describir el objeto desde su conteni-

${ }^{24}$ Meinong 1972a, p. 491; las cursivas son mías. 
do, y precisamente desde la esencia del contenido, ya que es su esencia lo que interesa a la ciencia. Hay ciencia de esencias indiferentemente si existen o no, si existieron o van a existir, etc. Incluso antes de saber si existe o no - como afirma Meinong-, se ha de saber la naturaleza de lo que se investiga, su esencia, y es a esto a lo que denomina "objeto puro", la esencia del objeto, el contenido esencial del objeto. Desde esta perspectiva, la esencia del contenido del objeto es independiente no sólo de su existencia o no, sino también de su estar siendo objeto, y por consiguiente, de su correlato psicológico: en la definición de la materia o contenido del objeto no entra su forma, esto es, su ser-objeto. Meinong piensa que esto es lo que pasa en las descripciones que hace la ciencia de su objeto. En la descripción de un fenómeno físico, por el mero hecho de describirlo, se lo está haciendo objeto, término de un acto intencional; pero en la descripción de ese fenómeno - que pertenece al contenido del objeto- no entra para nada el hecho de que se lo está haciendo objeto (la forma del objeto), esto es, que está siendo término de una actividad intencional. El sujeto cognoscente no entra para nada en la descripción del contenido esencial del objeto, su esencia (Sosein). Por ello, Meinong puede decir que la esencia del objeto está más allá del ser y del no ser, y que es un estado de allende el ser. La cuestión del ser que un determinado objeto tenga es asunto del objetivo, que es el objeto propio del juicio.

\section{Los cuatro estados del objeto: existencia, subsistencia, pseudoexistencia y aussersein}

El objeto (Objekt) puede encontrarse en cuatro estados: existencia, subsistencia, pseudoexistencia y allende el ser. Un objeto puede existir (este caballo), puede subsistir (el número cinco), puede pseudoexistir (el árbol en cuanto que está siendo imaginado por mí ahora), o únicamente tener el estado de allende el ser (el cuadrado redondo).

Lo interesante de estos cuatro estados del objeto es que hay cierta jerarquía entre ellos. Todo objeto (Objekt) que existe tiene que subsistir y tener el estado de allende el ser, pero no al revés. Todo objeto $(O b-$ jekt) que subsiste tiene que tener el estado de allende el ser, pero no viceversa. Y todo objeto (Objekt) que ni existe ni subsiste - como los imposibles - tienen al menos el estado de allende el ser (aussersein). Este estado es el estado del objeto puro, el objeto qua objeto, en su estado puro de allende el ser, que es un estado siempre presente en todo objeto, ya tenga el ser como existencia, ya lo tenga como subsistencia, 
o simplemente no tenga ningún tipo de ser. Todo objeto, por el mero hecho de ser objeto, tiene aussersein.

Por ejemplo, el objeto (Objekt) árbol es un objeto extramental, que tiene existencia. Pero este mismo objeto, en cuanto que está siendo considerado por la representación y se lo puede hacer objeto de reflexión, es mental, o más exactamente, el objeto es considerado sólo intencionalmente, cuyo ser es la pseudoexistencia, el puro y simple serrepresentado, por el cual el objeto árbol es un objeto-de-representación. Todo objeto existente, en su consideración directa, tiene ser como existencia; pero en su consideración reflexiva tiene ser como pseudoexistencia. Lo mismo se tiene que decir de todo objeto subistente - por ejemplo, el número cinco-, que en su consideración directa tiene ser como subsistencia, pero que en su consideración reflexiva tiene ser como pseudoexistencia. E independientemente de que se lo considere directa o reflexivamente, en su ser extramental o mental, hay un cuarto estado del objeto que es independiente de esos tres estados, es el estado puro del objeto, absoluto en cualquier consideración de ser.

La esencia del objeto árbol tiene existencia extramental, y tiene otra existencia mental o pseudoexistencia cuando se lo representa; pero, como tal, la esencia árbol puede describírsela sin ninguna referencia al ser, a saber, si existe o tan sólo es representada (pseudoexistencia). Cuando un botánico describe una especie de árbol, para nada entra en la descripción del objeto que estudia la consideración ontológica de su existencia ni la consideración gnoseológica de su pseudoexistencia; simplemente considera la esencia del árbol como si estuviera en un estado puro o absoluto, más allá del ser o del no ser. Todas las notas que se prediquen del objeto en su estado puro son todavía válidas cuando se le atribuye un ser extramental o si simplemente se lo considera, en el estado reflexivo de nuestra conciencia, como un objeto que se lo está representando (pseudoexistencia). Para describir la esencia biológica del árbol es completamente superfluo la inclusión del ser como existencia en sus notas, así como su ser-representado. La esencia biológica del árbol es la misma tanto si existe como si no existe, tanto si es pensada - y entonces tiene un ser en la representación o pseudoexistenciacomo si no lo es. Nada añadirá a la esencia biológica del árbol el serrepresentado o el ser como existencia.

Hay un claro paralelismo entre la doctrina meinonguiana de los estados del objeto y la del filósofo escocés Duns Scoto, que trata la cuestión de los tres estados de la esencia como un problema del objeto de la metafísica. Sin entrar en los análisis particulares del filósofo escocés, se 
quiere llamar la atención sobre el paralelismo entre los dos filósofos en este asunto. Duns Scoto sostiene que la esencia puede encontrarse en tres estados: la esencia real, que existe extramentalmente; la esencia mental, que existe objetivamente, cuyo ser se reduce al ser objetivo de la representación, y el tercer estado es la esencia precisivamente considerada (esencia en su estado absoluto), esto es, abstraída de su ser real y ser objetivo en la mente. Según Duns Scoto, el objeto de la metafísica no es la esencia real, ya que también trata de los entes de razón, sino la esencia que prescinde de su condición extramental y mental, pero que a la vez puede ser predicada del ser real y del ser objetivo de la mente, pues ni los excluye ni los incluye.

Meinong y Duns Scoto parecen sostener la misma doctrina, que el primero llama "del objeto puro" y el segundo "del estado puro de la esencia", que ni excluye ni incluye el ser extramental (existencia o subsistencia) ni el ser mental (pseudoexistencia). Por ejemplo, el objeto árbol puede considerárselo en su ser existente, pero también se lo puede considerar en su ser mental, que todo objeto tiene por el mero hecho de ser representado (un ser en la representación o pseudoexistencia), pero también cabe considerarlo en sí mismo, en su esencia, independientemente de si existe o está siendo representado, pero que a la vez no excluye que exista o sea representado, ni incluye que exista o sea que es representado. De esta suerte, el objeto puro, el objeto qua objeto, o el objeto esencialmente considerado, que para Meinong serían equivalentes, acompaña a todo objeto: el objeto puro se da en el objeto existente, subsistente y en el objeto en cuanto representado. Todo objeto existente tiene una esencia que es idéntica a la del objeto que es representado, lo que implica que esta esencia es indiferente a darse con un ser existente o meramente representado (pseudoexistencia).

\section{BIBLIOGRAFÍA}

Brentano, Frank, 1924, Psychologie vom empirischen Standpunkt, 2a. ed., Felix Meiner, Leipzig.

Kotarbinski, Tadeusz, 1976, "Franz Brentano as Reist", en Linda L. McAlister (comp.), The Philosophy of Brentano, Duckworth, Londres, pp. 194-203.

Lambert, Karel, 1983, Meinong and the Principle of Independence, Cambridge University Press, Nueva York.

Meinong, Alexius, 1978a, Über Annahmen, en Gesamtausgabe IV.

— 1978b, Über Möglichkeit und Wahrscheinlichkeit, en Gesamtausgabe VI.

— 1978c, Selbstdarstellung, en Gesamtausgabe VII.

_, 1972a, Über Gegenstandstheorie, en Gesamtausgabe II. 
Meinong, Alexius, 1972b, Über Gegenstände höherer Ordnung und deren Verhältni 3 zur inneren Wahrnehmung, en Gesamtausgabe II.

_, 1972c, Über emotionale Präsentation, en Gesamtausgabe III.

— , 1969-1978, Gesamtausgabe, ed. Rudolf Haller, Rudolf Kindinger y Roderick Chisholm, 8 vols., Akademische Druck und Verlagsanstalt, Graz.

Routley, Richard, 1980, Exploring Meinong's Jungle and Beyond, Departmental Monography No. 3, Philosophy Department, Research School of Social Sciences, Australian National University, Canberra.

Russell, Bertrand, 1938, The Principles of Mathematics, W.W. Norton, Nueva York.

Velarde-Mayol, Víctor, 1998, "El concepto de metafísica en la filosofía analítica", en Concepciones de la Metafísica, Enciclopedia Iberoamericana de Filosofía, no. 17, Editorial Trotta/Consejo Superior de Investigaciones Científicas, Madrid, pp. 311-340.

— 1989 , La teoría del objeto en Alexius Meinong, Editoral de la Universidad Complutense de Madrid, Madrid.

Recibido el 9 de febrero de 2006; aceptado el 28 de septiembre de 2006.

Diánoia, vol. LII, no. 58 (mayo 2007). 